\title{
Quantifying the Value of Investing in Distributed Natural Gas and Renewable Electricity Systems as Complements: Applications of Discounted Cash Flow and Real Options Analysis with Stochastic Inputs
}

By Jacquelyn Pless, a,b Douglas J. Arent, a Jeffrey Logan,c Jaquelin Cochran,c and Owen Zinamanc

June 16, 2016

\author{
a Joint Institute for Strategic Energy Analysis (JISEA) at the National Renewable Energy Laboratory (NREL), 15013 \\ Denver W Parkway, Golden, CO 80401 \\ ${ }^{b}$ Colorado School of Mines, 816 15th Street, Engineering Hall, Golden, CO 80401 \\ c National Renewable Energy Laboratory (NREL), 15013 Denver W Parkway, Golden, CO 80401
}

\section{Corresponding author:}

Jacquelyn Pless, Colorado School of Mines

$81615^{\text {th }}$ Street, Engineering Hall

Golden, C0 80401

jacq.pless@gmail.com

Phone: 802-825-1068

\begin{abstract}
One energy policy objective in the United States is to promote the adoption of technologies that provide consumers with stable, secure, and clean energy. Recent work provides anecdotal evidence of natural gas (NG) and renewable electricity (RE) synergies in the power sector, however few studies quantify the value of investing in NG and RE systems together as complements. This paper uses discounted cash flow analysis and real options analysis to value hybrid NG-RE systems in distributed applications, focusing on residential and commercial projects assumed to be located in the states of New York and Texas. Technology performance and operational risk profiles are modeled at the hourly level to capture variable RE output and NG prices are modeled stochastically as geometric OrnsteinUhlenbeck (OU) stochastic processes to capture NG price uncertainty. The findings consistently suggest that NG-RE hybrid distributed systems are more favorable investments in the applications studied relative to their single-technology alternatives when incentives for renewables are available. In some cases, NG-only systems are the favorable investments. Understanding the value of investing in NG-RE hybrid systems provides insights into one avenue towards reducing greenhouse gas emissions, given the important role of NG and RE in the power sector.
\end{abstract}

Keywords: real options; project valuation; energy sector; renewable electricity; natural gas

JEL codes: G11; G32 


\section{Introduction}

Although natural gas (NG) and renewable electricity (RE) have traditionally competed for market share in the United States power sector, there is growing potential for the two to be used synergistically as complements. Both NG and RE benefit from abundant domestic resource bases, and for electricity generation, they exhibit different but complementary cost and operational risk profiles. Power from RE technologies hedges fuel price risk that is introduced by NG-fired generation given its zero fuel costs (and thus low and stable operation and maintenance (O\&M) costs), but it requires higher upfront capital expenses. On the other hand, NG-fired generation requires lower capital costs and has the ability to rapidly ramp output in response to variable output from some RE sources, particularly solar and wind. The alignment of NG and variable RE (VRE) operational and cost profiles suggests that NG and VRE have potential to work as complements as opposed to competitors.

While recent work provides anecdotal evidence of NG-RE synergies in the power sector (e.g., see Lee et al. (2012) and Cochran et al. (2014)), few studies in the literature quantify the value proposition of project-level end-use applications comprised of both NG and RE. Some analyze the complementary nature of NG and RE at the grid level, take a portfolio optimization approach to analyze an electricity portfolio, or analyze singletechnology distributed generation applications, but to our knowledge, these studies do not examine project-level case studies that consider the use of both RE and NG in harmony. The purpose of this paper is to fill this gap by quantifying the value of investing in hybrid NGVRE relative to their single technology alternatives or business-as-usual in distributed applications. We focus on stand-alone configurations for single homes and critical services buildings composed of NG microturbines and solar photovoltaics (PV), two technologies that are commercially available today and which have sufficient public data to enable valuation of these systems while also allowing hourly operations to be modeled. We 
implement two different methodologies, traditional discounted cash flow (DCF) and real options analysis (ROA) frameworks. This provides robustness to the findings, showing that the conclusions are constant despite which method is used. It also provides insight about the implications of fuel price volatility and electricity rate structure for valuation. Lastly, we focus on project economics in New York and Texas, two states that offer comparative investment conditions given their distinct energy resource bases, market conditions, and climates.

The remaining of this paper is organized as follows. Section II provides motivation for our choice of applying both DCF and ROA methodologies. Section III summarizes existing research in this area and highlights the gaps in the literature that we hope to narrow. Section IV identifies cash inflows and outflows for DG systems and describes how DCF and ROA are applied. Section V details the natural gas price modeling methodology, as it is the main source of uncertainty captured in this analysis and is characterized by a stochastic process. The business case designs and assumptions are provided in Section VI, and Section VII summarizes results. The paper concludes in Section VIII with an overview of policy implications and areas ripe for future research.

\section{Methodology Overview}

From the consumer's perspective, or the system owner end-user's perspective, investment decisions concerning distributed generation (DG) units theoretically involve some assessment of uncertainty in electricity and fuel prices. The former are considered relatively fixed for utility customers (either through standard or time-of-use (TOU) rate structures), but the latter introduce significant uncertainty, which has implications when considering cash flows from energy investments. While DCF analysis provides tractable and easily interpretable investment decision-making support, it ignores characteristics inherent to 
power generation investments, namely uncertainty and irreversibility, and it assumes that the underlying conditions are stationary and definite throughout project life. ${ }^{1}$

This can be a costly assumption when cash flows are actually uncertain, which is the case for many energy investments. The value of power generation technologies is a function of the system's expected lifetime, investment costs, financing structure, and discounted cash flows, the last of which comprises several underlying uncertain and often volatile system attributes related to operations and output, the price of fuel, technological efficiency, technology costs, and the price of electricity. Traditional DCF assumes predefined and constant discount rates even though risk varies depending on technology, performance, and the other aforementioned risks. ${ }^{2}$ Uncertainty in DCF can be handled in a risk-adjusted discount rate, but this is still a static treatment of uncertainty that does not account for the dynamic variation of cash flow risk through time.

On the other hand, more advanced methodologies have been developed to account for uncertainty, such as probabilistic DCF as well as DCF within a portfolio of scenarios. Rather than taking this approach, we focus on modeling the uncertainty of input prices (stochastic NG prices and the hourly variability of RE output) given their implications for the relative risk profiles of NG and RE, which are then projected into DCF over time and expressed in NPV terms. This allows us to capture the complementary risk profiles of NG and RE at the hourly level in our valuations.

An alternative valuation tool to overcome some of the limitations of DCF is the stochastic modeling approach of Real Options Analysis (ROA), which incorporates uncertainty directly into the investment model. Options analysis originated in the field of finance (Myers, 1984) and has been developed for use of management and budgeting

\footnotetext{
${ }^{1}$ This is only one construct of DCF, however. One could project variable prices (as we do in this analysis) into DCF over time and then express this in NPV terms.

2 It is important to note that although DCF techniques assume constant discount rates, the net present value method can easily accommodate the term structure of interest, which makes it an advantage over the internal rate of return method.
} 
decisions since the early 1990s (Dixit and Pindyck, 1994; Trigeorgis, 1996; Amran and Kulatilaka, 1999; Copeland and Antikarov, 2001).

The intuition behind ROA is this: having options allows for gains on the upside of uncertainty and reductions on downside potential. Thus, the ability to make decisions in reaction to risk skews the distribution of possible outcomes towards the upside, increasing the overall value of the project. When investments are characterized by uncertainty and irreversibility, the traditional NPV rule can be wrong (Pindyck, 2008) and valuation grounded in pricing options is sometimes viewed as superior (Dixit and Pindyck, 1994; Sick, 1995; Trigeorgis, 1996; and Abadie and Chomorrow, 2009). Ultimately, ROA allows for better treatment of volatility relative to DCF so that the extent of uncertainty and its implications are not underestimated.

Energy investments are particularly suitable for ROA, exhibiting unique characteristics that distinguish them from many other investments. First, they are at least partially (if not completely) irreversible. Second, they are subject to significant uncertainty as they face price volatility, technological change, and policy and regulatory uncertainty, and ROA explicitly reflects the impact of volatile input prices on investments. Power generation investments face many sources of risk that change throughout time, and assets consisting of both NG and RE technologies add even more uncertainty to the investment decision relative to single-technology assets since both fuel price volatility and RE output variability impact returns. In general, when uncertainty is high, there is greater value in the option to invest, and thus there is a greater incentive to keep options open (Pindyck, 2008).

Any decision that involves sunk costs can be viewed in a ROA framework, such as opening or closing a mine, installing scrubbers on a coal-burning power plant, or signing a long-term fuel contract. When the "investor" is a homeowner or firm considering distributed energy solutions, one can imagine ROA applications in the context of having the 
option to invest in a DG project beyond a business-as-usual (BAU) case of purchasing electricity and NG from local utilities. This "option to expand" is the case explored here, as it is possible to wait for more information before exercising the option since there exists an opportunity cost associated with investing now rather than waiting.

This paper focuses on the option to expand given a priori that the investment decision-maker is considering a DG system relative to BAU, implementing both a traditional DCF analysis and a ROA for valuing NG-RE hybrid investments relative to their singletechnology alternatives. Presenting results from both DCF and ROA perspectives provides robustness and a higher degree of confidence in our findings. It also demonstrates the implications of fuel price volatility and electricity rate structure for valuation.

\section{Existing Research on NG-RE Hybrids}

Existing research on the value of pairing electricity technologies mostly focuses on how RE mitigates fuel price risk within an electricity generation mix. Portfolio optimization techniques are applied to demonstrate the value of reducing portfolio risk in energy applications. For instance, Bolinger et al. (2002) apply such methods to quantify the value that wind power provides as a hedge against NG price volatility, demonstrating the price stability benefit that wind and other renewables provide to a portfolio of electricity generating technologies. Similarly, Bush et al. (2012) conduct a variance analysis of wind and natural gas generation under different market structures, and Jenkin et al. (2013) examine the use of solar and wind as a physical hedge against price variability within generation portfolios. ${ }^{3}$ However, these analyses do not compare the value of project-level

\footnotetext{
3 Applications in the energy sector date back to the seminal work of Shimon Awerbuch (Awerbuch 1993, 1996, 2000a, 2000b, 2004, and 2007). Other applications include Blyth (2006), Blyth et al. (2007), Liu (2007), Gross et al. (2009), and Delarue et al. (2010).
} 
hybrid NG-RE systems relative to alternative single-technology investments. Rather, they demonstrate the risk-hedging benefits of a portfolio of electricity generation technologies.

Some studies apply DCF and ROA methods to value energy investments, however they mostly focus on single technology assets. For example, Kashani et al. (2012), Abadie and Chamorro (2012), and Santos et al. (2014) apply ROA to renewable energy projects, and van Heeswilk (2012) and He (2007) apply ROA to natural gas projects. They do not consider projects that incorporate both NG and RE components, however, which fundamentally changes the underlying cash flows and sources of uncertainty.

On the other hand, some recent work is starting to explore ROA methods applied to hybrid projects such as microgrids and in the context of electricity generation planning, however there remains room for contribution. For example, Asano et al. (2010) examine investment strategies in a microgrid system consisting of renewable power generation and a cogeneration system under uncertainty in NG prices. The authors use ROA to value microgrids, however the valuations are not considered relative to NG-only and RE-only comparable alternatives. Rather, the paper focuses on demonstrating how solar PV generation reduces risk as NG prices increase. Siddiqui and Marnay (2008) examine a California-based microgrid's decision to invest in an NG unit, however the focus is on operational flexibility and the NG generation cost threshold that triggers investment as opposed to valuation of alternative investment options. Other studies focus on applying ROA to the decision to shut down power plants or when to operate certain segments of the system, ${ }^{4}$ however these questions are fundamentally different than initial DG investment decisions beyond BAU, which is the focus of this research.

\footnotetext{
${ }^{4}$ For instance, Kienzle and Andersson explore operational flexibility of multi-energy generation plants. Other examples in renewable energy include Siddiqui et al. (2007) and Davis and Owens (2003), and an example of the effects of carbon price caps on electric investments can be found in Szolgayova et al. (2008). Again, see Fernandes et al. (2011) for a full review of ROA applications to energy projects.
} 


\section{Cash Flows and Methodology Application}

\subsection{Identifying Cost and Revenue Streams for DG Systems}

Both DCF and ROA rely on present value calculations of annual cash flows. Cash inflows include savings from reduced electricity and NG utility bills, incentives (both federal and state), and tax benefits. Cash outflows include initial investment outlay and installation costs, fixed and variable operating and maintenance (O\&M) costs, tax liabilities, and loan principal and interest payments. Table 1 summarizes the cash flows considered here.

Capturing the costs and revenues on an annual basis, however, first requires modeling the hybrid NG-RE, NG-only, and RE-only system operations at the hourly level so that the amount of each resource consumed is captured realistically given technology performance and operational profiles. NG and RE technologies face uncertainties in fuel prices and output, respectively, and modeling operations hourly captures these risks. The method for modeling hourly operations is detailed in Section 5.

Once estimates for hourly output and demand for each resource are calculated, electricity and NG bill payments that would have been incurred and paid to local utilities without a DG system can be calculated. These are considered cash inflows. Although avoided bill payments are not necessarily revenues, they are avoided costs and thus classified as inflows for this analysis. Costs incurred from operating the system (as well as any costs incurred from residual demand that is still met by local utilities) can be found at the hourly level based on given electricity and NG utility rate structures. Appendix A provides the utility-specific structures assumed in this analysis under standard and time-ofuse (TOU) options for both residential and commercial consumers in Suffolk County, NY and Waco, TX, the two locations selected for the hypothetical business cases studied here. Section 5 discusses specific business case system design and performance, cost, and financing assumptions. 


\subsection{Discounted Cash Flow Analysis}

Traditional DCF entails maximizing the NPV of cash flows. The sum of the present values of annual cash flows are calculated as

$$
N P V=-I_{0}+\sum_{t=1}^{N}\left(\frac{E\left(C F_{t}\right)}{(1+r)^{t}}\right)
$$

where $I_{0}$ is the initial investment outlay, $E\left(C F_{t}\right)$ is expected cash flow in period $t$, and $r$ is the discount rate. Generally, if the NPV is greater than zero, the investment is viewed as attractive. In the applications pursued here, however, the objective is to compare DG investment options between the system configurations, so the NPV with the highest value relative to comparable systems (and BAU) indicates the most economically attractive investment option. Even if the NPV is negative, it could be the best option given the alternatives. This is particularly relevant when comparing the DG investments to BAU, where BAU consists of only cash outflows, so a less negative NPV from a DG system relative to BAU is more attractive than BAU.

More sophisticated DCF methods that account for some uncertainty exist, however as described in Section IV, we focus on modeling the uncertainties in input prices. We project stochastic NG prices over time and use variable hourly solar PV projections to capture the inherent uncertainty in RE generation and express these in NPV terms. This approach allows us to compare a more advanced DCF analysis (but not scenarios or probabilistic DCF) to the ROA approach described in Section 3.3.

\subsection{ROA Application: The Option to Expand}

The "option to expand" values the flexibility to expand from an existing state (BAU, which is purchasing $100 \%$ of both electricity and non-electric NG from local utilities) to an expanded state (installing a stand-alone DG system). This can be viewed in the context of an American 
call option, which is the right to buy, and the call option is the commitment of capital for the investment. Specifically, the option to expand here considers the value of investing in a DG system to move from BAU to a new state where load is met by an onsite system.

American call options provide the option to invest (exercise the option) in the underlying asset at some fixed price (the strike price) at any time preceding the option's expiration date, and the buyer pays a price for this right. The value of the underlying asset is the present value of positive cash outlays and the strike price is the present value of negative cash outlays over project lifetime. The time to maturity is how long the owner can wait until it must exercise or abandon the option. While this choice is arbitrary and can be perpetual, the current analysis imposes a 10-year expiration time since many renewable portfolio standard (RPS) or goals have deadlines within the next ten years. Table 2 provides an analogy of call options relative to project characteristics that are applicable in considering DG investments.

If the value of the underlying asset exceeds the strike price at expiration, then the buyer makes profits equal to the difference between the value of the underlying asset $(V)$ and the strike price $(K)$. If not, then the buyer will not exercise the right. As the value of the underlying asset increases, the value of a call increases, and vice versa. Overall, as the underlying asset price increases and the strike price decreases, the call value increases. Other key determinants to valuation of an American call option include the variance (volatility) of the underlying asset and the time to expiration, which increase the option value as they increase.

Following Damodaran (2012), the value of a call option can be calculated as

$$
\text { Call Value for Option to Expand }=V * N(d 1)-K e^{-r t} N(d 2)
$$

where $V$ is the value of the underlying asset (or the present value of positive cash inflows, such as avoided utility bills), $K$ is the strike price (or the present value of negative cash 
outlays, such as investment and new operating costs), $r$ is the risk-free rate, $t$ is time until option expiration, and $N$ as a function calculates the probability that observed values of a standard normal random variable will be less than or equal to $d 1$ and $d 2$. For the option to expand,

$$
\begin{gathered}
d_{1}=\frac{\ln \left(\frac{V}{K}\right)+\left(r+\frac{\sigma^{2}}{2}\right) t}{\sigma \sqrt{t}} \\
\text { and } \\
d_{2}=d_{1}-\sigma \sqrt{t}
\end{gathered}
$$

The replicating portfolio is thus embedded in the Black-Scholes model, and in order to replicate this call option, the owner needs to buy $N(d 1)$ shares of the underlying asset, which is referred to as the option delta. Furthermore, the owner would need to borrow $K e^{-r t} N(d 2)$ (Damodaran, 2012).

The volatility associated with the underlying asset, $\sigma$, is one of the critical features of ROA, and estimating $\sigma$ is not trivial. Here, it is defined as the volatility of natural gas prices since this is the only stochastic process characterized in this analysis. Section 4 describes the approach to modeling natural gas prices as applied throughout this analysis. Accounting for the features of the stochastic price path (volatility, mean-reversion, and trend) has critical implications for options pricing with direct impacts on the probability of reaching various valuation barriers during the life the option, particularly when the market is highly volatile as in most power markets (Blanco and Soronow, 2001).

Interpreting the option value is similar to interpreting the NPV for investment decision-making. In the ROA context, however, the NPV is reformulated so that scenarios of greater uncertainty are considered. One can think of this value as an "expanded" NPV, which is equal to the traditional or static NPV plus some value related to flexibility. Investment decision-making rules based on this expanded NPV (the real option value (ROV)) are similar 
to those described in Section 3.2 for NPV, where the less negative ROV indicates the more attractive investment option when comparing systems.

\section{Natural Gas Price Modeling}

One key determinant and source of uncertainty for energy assets is that of fuel costs, and capturing the stochastic nature of NG price is critical for investment valuation. ${ }^{5}$ However, careful consideration of how to characterize and forecast NG price paths is warranted. Estimating volatility with a simple standard deviation tends to lead to forecasts that overestimate volatility since it does not account for mean-reversion, a characteristic that NG prices exhibit. Furthermore, assuming that NG prices follow a random walk can lead to a vastly different investment decision than operating under the assumption that prices follow a mean-reverting process or mean-reverting to a trend line (see Baker, Mayfield, and Parsons (1998) for examples of different price process models and their implications for valuation and investment decision-making). Many methods for modeling natural gas prices have been developed. However, identifying which approach is most appropriate for long run forecasting is not trivial and depends on the stochastic process that the prices actually follow (Pindyck, 1999).

In recent years, the U.S. natural gas market has experienced dramatic changes, not only as a result of the domestic shale boom but also following a deregulation period and elimination of monopolies over the past few decades. The market has become relatively robust with market trading activity, and a number of fundamental price drivers, such as issues relating to weather, storage, transportation, extraction, policy, and technological change, create complex NG price behavior and uncertainty.

\footnotetext{
${ }^{5}$ Since energy investments exhibit option-like traits, the second moments of the price processes underlying the investment decisions are relevant. As such, stochastic process price models describing the evolution of a system or time series are often used in dynamic models of uncertainty, and especially price uncertainty (Dixit and Pindyck, 1994).
} 
Although both price levels and volatility have decreased since the shale boom (Gotham et al., 2013) with the rise of domestic production and a positive supply balance, short-term inelasticity of supply and demand as well as infrastructure and supply constraints from storage still lead to volatile spot markets, particularly during high demand periods and extreme weather conditions. Since price behavior is largely determined by uncertain events such as unknown future demand for NG and exports, policy regulation, seasonal patterns, and infrastructure constraints, volatility remains prominent (but generally with a different magnitude than in pre-shale boom years) and many markets remain extremely price-sensitive.

At the same time, NG spot prices are mean-reverting processes (Dixit and Pindyck, 1994; Pindyck, 1999; Swishchuk, 2008; Parsons, 2011), and they revert to trend lines (Pindyck, 1999). In other words, prices move up and down (frequently) but they revert to a long-run mean that is determined by a trend line. Although projections indicate that NG prices will likely remain relatively low for at least a decade, a long-term upward trend is still expected given theories of exhaustible resource production, and thus inclusion of a mild trend is important.

A number of models have been proposed for representing the stochastic process that commodity prices follow. The differences among them generally relate to the number of risk factors required to describe uncertainty and how convenience yield is specified (Abadie and Chomorro, 2009). Some note that three factors (spot prices, interest rates, and convenience yields) are required to capture future price dynamics (e.g. Schwartz, 1997). On the other hand, Schwartz and Smith (2000) present a two-factor model with a meanreverting short-term disturbance in prices and a long-term price level that follows a Brownian motion. These two factors can be estimated from spot prices. 
Models that use a 'random walk' under geometric Brownian motion (GBM), which are commonly implemented, assume that price changes are independent of one another. However, this implies that the historical path that prices followed to achieve current price is irrelevant for predicting future price paths. This is unrealistic for the case of NG. On the other hand, mean reversion allows for the random walk to be modified so that price changes are related (Blanco and Soronow, 2001). It essentially allows price to be determined by the distance between current price and the mean-reversion level (or trend line), as well as the rate of mean reversion, so that if the spot price is below (above) the mean level or trend line, the process will be driven upwards (downwards). The price path ultimately drifts towards the mean or trend line at a speed determined by the mean reversion rate (Blanco and Soronow, 2001).

One stochastic process that captures the mean-reverting characteristic that NG prices exhibit and which is commonly employed for simulating NG spot prices is the geometric Ornstein-Uhlenbeck (OU) stochastic process. This model is a modification the standard GBM and allows the volatility of price to depend upon price level (Gjolberg and Guttorsmen, 2002; Insley and Rollins, 2005, Insley and Chen, 2012). The geometric OU process can be further modified to include a trend, as well. Therefore, this is the mechanism employed in this analysis to simulate NG prices over the project life. The advantage of using this model is ease of calibration and a simple form for the futures price. Furthermore, it can be readily discretized from its continuous time form, which is appropriate for the consideration of monthly price projections. ${ }^{6}$

For this analysis, the parameters for a geometric Ornstein-Uhlenbeck stochastic process with trend are calibrated using logged monthly Henry Hub spot price averages from

\footnotetext{
${ }^{6}$ Since utilities generally determine end-use NG prices on a monthly basis, a NG price projection at the monthly level is applied here.
} 
2009 to $2013 .^{7}$ Although spot price data are available back to 1997 , the parameter estimates for volatility and long-run mean will be different in the post-shale boom era. Prices still exhibit the same characteristics as before the boom, but the level, volatility, and meanreversion rate parameters are likely of different scales. Using only post-shale boom data reflects the current market and expected price path behavior. Lastly, the use of monthly prices (as opposed to daily) is warranted since utilities generally price natural gas delivered to residential and commercial end-users on a monthly basis for billing purposes.

Once the stochastic process parameters for average monthly spot prices are calibrated, monthly natural gas spot price averages are simulated in discretized form, which are then used for modeling the market-driven supply component of NG retail rates. ${ }^{8}$ Utilities generally determine $\mathrm{NG}$ retail rates for residential and commercial end-users by incorporating both market (variable) and non-market (fixed) variables, where the supply price component is market-driven (i.e., determined by spot prices). In this analysis, utilityspecific historical monthly supply prices are regressed on historical monthly Henry Hub spot price averages to estimate a linear model (for only the supply component of NG retail rates), which is then used to project the supply price component over the asset's lifetime. The fixed components of end-use NG prices are treated differently-a simple fixed escalation rate of $2 \%$ is applied. ${ }^{9}$

From this calibration, estimation, and projection procedure, monthly cash flows related to the NG components of the project are calculated and aggregated to the annual level.

\footnotetext{
7 The log-normal distribution allows for only positive price outcomes while also remaining applicable within the basic BlackScholes framework since the natural log of prices is normally distributed.

${ }^{8}$ The stochastic process only captures the supply component of NG prices for end-users. Utilities typically determine the price of NG delivered to end-use customers based on the market spot prices, which drives the supply component, as well as a number of fixed components.

${ }^{9}$ This is the exact procedure applied for the New York case studies, but utility-specific NG retail rates were not available for the Texas cases. Instead, the same calibration procedure was followed, but historical state-level average residential and commercial NG retail rates were used for estimating the linear model rather than utility-specific supply rates.
} 


\section{Business Case Design \& Assumptions}

The hypothetical cases studied here consider applications for a single home and a critical services building (a hospital) in Suffolk County, New York and Waco, Texas, which exhibit contrasting market structures, policy environments, climates, and end-user load profiles. The goal is not to optimize system design or operations for a given site but rather to focus on modeling inputs that capture the different resource risk profiles and to value the systems in a way that enables comparison. Thus, system sizes for solar PV are determined exogenously and then appropriate NG microturbine sizes are calculated according to operating assumptions and industry standard performance assumptions (see Section 5.3.2 for details on microturbine sizing).

Operationally, modeling the NG and RE components of the hybrid system must capture factors such as the electricity load profile, non-electric natural gas demand (for heating), electricity rate structures, RE output, NG prices, and NG price volatility, each of which impacts system operations, costs, and revenues. This analysis characterizes operations at the hourly level over a 25-year project lifetime for residential applications and a 30-year project lifetime for commercial applications. ${ }^{10}$ Conducting the analysis at the hourly level allows for the use of location-specific data and an understanding of how various market features impact investment attractiveness. This section describes the operating and technology assumptions used for calculating hourly system outputs, which are then used as inputs for cash flow calculations.

\footnotetext{
10 These are conservative assumptions. The expected useful life of solar PV systems is generally expected to be 30 to 40 years according to some sources (SunPower 2012) and 25 to 30 years according to others (REC Solar, 2014). NREL typically assumes 30 years (see sam.nrel.gov/financial). We use an even more conservative assumption of 25-year life for residential systems because most solar systems come with a 25-year warranty for performance.
} 


\subsection{Load Profiles}

Simulated hourly residential and hospital building NG and electricity load data were obtained from publicly available datasets, which are available for all typical meteorological year (TMY) 3 locations in the United States (OpenEI, 2013). The datasets contain hourly load profile data for 16 commercial building types as well as residential buildings. The simulations consider variations in building types and they incorporate differences in construction due to local climate. For the residential homes considered here, a "high-load" case is assumed where the building ranges from 3000 to 4044 square feet, and has 4 bedrooms and 2.5 bathrooms. The commercial building application uses hourly simulations for a hospital. All building characteristic details for residential hourly load data are based on the Building America B10 Benchmark (Hendron and Engebrecht, 2010).

The simulated NG load profiles are provided in kilowatt-hour units; however, utilities typically bill on a per Therm basis. Thus, conversions are needed to calculate how much fuel in Therms is required to generate the kilowatt-hours (kWh) of NG demand, which depends on the efficiency (heat rate) of the generator and the heat content of the fuel. The formal conversions for determining hourly NG demand in Therms are detailed in Appendix B.

\subsection{Operating Assumptions}

The DG systems are assumed to fully meet onsite electricity demand as well as non-electric NG demand (for heating), and hourly operations follow profit-maximizing consumer problem assumptions in which a spark-spread analysis determines hourly consumption of solar PV and NG. The spark-spread, $S$, is defined as the difference between revenues (electricity prices) and variable 0\&M costs, which include the price of fuel used to generate power plus other variable $0 \& M$ costs. Consumers, therefore, face the following sparkspread profit-maximizing criteria: 


$$
\max S=S_{e}-F_{H} S_{g}
$$

where $S_{e}$ is the price of electricity, $S_{g}$ is the cost of fuel used for generating electricity, and $F_{H}$ is the heat rate, the amount of natural gas in British Thermal Units (BTUs) required to generate $1 \mathrm{kWh}$ of electricity. The spark-spread yields its holder the positive part of electricity price less the "strike" - which is the heat rate-adjusted fuel price (or the dispatch cost). Heat rates measure plant efficiency where more efficient plants have lower heat rates. Although heat rates can vary for given systems, constant heat rates are often assumed for long-term analyses (e.g., see Deng et al., 2001).

The decision to dispatch in any given hour depends on whether the hourly price of power exceeds the cost of fuel needed to generate that power. Generally, the system operates only when it is economically efficient to do so (when the spark spread is positive), but in this study, the system is assumed a priori to always operate to meet onsite demand. Which component (solar PV or NG) operates, however, is determined by which source produces the more positive spark spread. Since both NG and solar PV face the same electricity price, the main factor determining which system component operates is the fuel cost plus other variable O\&M costs. Solar PV will always be favored in this case as it faces no variable $0 \& M$ costs while generating electricity from NG microturbines incurs the cost of fuel. In other words, when solar output exists, the spark-spread for solar will always exceed the spark-spread for natural gas, and thus solar PV output will always be more economical to consume when it exists and there is demand.

This translates into $100 \%$ of hourly solar output being consumed hourly while residual electricity demand is met by the NG microturbine. The NG microturbine also serves non-electric (heating) NG demand. In the case that hourly solar output exceeds hourly demand, the excess output is either lost (if net metering is not an option) or it is aggregated 
monthly and rolled over to the next month (if net metering is available). We do not account for NG ramping time or costs. ${ }^{11}$

For the NG-only configurations, the system is assumed to meet all electric and nonelectric NG demand (even if the spark-spread is negative) as a stand-alone system. For the RE-only cases, $100 \%$ hourly solar output is consumed in that given hour (as in the NG-RE hybrid case), but residual electricity demand and non-electric NG demand is met by the local utilities. Table 3 summarizes these system design and operating assumptions.

\subsection{Technology Assumptions}

\subsubsection{Solar PV}

Location-specific hourly solar PV system output for one year was simulated in NREL's PVWatts tool for a $4 \mathrm{~kW}$ (DC) residential fixed array system for the single home residential applications and a 1.4 MW (DC) commercial fixed array system for the hospital applications. PVWatts simulations use hourly solar resource data that describe solar radiation and meteorological conditions at site-specific locations. Specifically, PVWatts uses the National Solar Radiation Database (1961-1990) (TMY2) data site nearest the system location. PVWatts default values are assumed for characterizing the solar PV system ${ }^{12}$ and the sizes of the systems were exogenously determined a priori. A $0.5 \%$ annual production degradation rate is applied to account for aging system components over project lifetime.

\subsubsection{Natural Gas Microturbines}

NG microturbines can operate as standalone onsite applications remote from power grids, offering many benefits to owners such as compact size, a small number of moving parts, the option to use waste fuels, long maintenance intervals, and improved efficiency when

${ }^{11}$ According to a discussion with an industry expert, the ramping time and costs for microturbines of this scale are negligible.

${ }^{12}$ These include: standard module type, fixed (open rack) array type, 14\% system losses, 20 degrees tilt, 180 degrees azimuth, 1.1 DC to AC size ration, $96 \%$ inverter efficiency, and 0.4 ground coverage ratio. 
combined heat and power (CHP) is included (EPA, 2008). However, they have low fuel-toelectricity efficiencies, and a loss of power output and efficiency with higher ambient temperature and elevation (EPA, 2008). Driven by small-scale gas turbines, their electrical efficiencies generally range from $26 \%$ to $33 \%$ (without CHP) but can achieve thermal efficiency of up to $85 \%$ with CHP. They can run continuously or on-demand, can be installed individually or via a multi-pack, and can stand-alone or connect to a grid. They have been commercially applied in residential and commercial buildings and can be generally scaled as needed.

Technology and performance assumptions in this analysis are primarily informed by reported figures from Capstone Turbine Corporation. The smallest microturbine sold by Capstone is about $30 \mathrm{~kW}$, however microturbines can be scaled to almost any size. For instance, Kohler Generators sells units as small as $6 \mathrm{~kW} \cdot{ }^{13}$ Net heat rates for small microturbines range from about $11,800 \mathrm{Btu} / \mathrm{kWh}$ to $14,700 \mathrm{Btu} / \mathrm{kWh}$, where less efficient systems are characterized by higher heat rates. ${ }^{14}$ Therefore, a higher heat rate is appropriate for smaller (less efficient) systems whereas a lower heat rate applies to larger (more efficient) systems. Fuel heat contents for microturbines (for gas HHV) generally range from $825 \mathrm{Btu} / \mathrm{scf}$ to $1275 \mathrm{Btu} / \mathrm{scf}$, with Capstone's 28kW system (Model 330) fuel heat content ranging from 700 to 2615 Btu/scf and Kohler Generators' 6kW system having a heating value of about $890 \mathrm{Btu} / \mathrm{scf}^{15}$

The analysis employed here assumes that the systems can be scaled down to the appropriate size for the case study's load profile, but the $30 \mathrm{~kW}$ per unit cost and performance specifications are used to ensure data consistency. ${ }^{16}$ The residential systems

\footnotetext{
${ }^{13}$ See: http://www.kohlergenerators.com/home-generators/generators.

${ }^{14}$ Capstone indicates that its $28 \mathrm{~kW}$ system (Model 330) has a heat rate of $13,000 \mathrm{Btu} / \mathrm{kWh}$ and that the fuel heat content ranges from 700 to $2615 \mathrm{Btu} / \mathrm{scf})$ :

http://physics.oregonstate.edu/ hetheriw/energy/topics/doc/elec/natgas/micro/SpecSheetlowpressureNG.pdf.

15 The system specifications can be found here: http://www.kohlergenerators.com/common/pdf/g4213.pdf.

${ }^{16}$ The per unit costs of smaller systems are likely higher than what is assumed here, but there is no data to inform higher cost assumptions.
} 
studied here are very small (ranging from $3 \mathrm{~kW}$ to $7 \mathrm{~kW}$ ), however this is not particularly unrealistic given that there are $6 \mathrm{~kW}$ systems on the market today, and our system efficiency assumptions are similar to the specifications for systems as small as $6 \mathrm{~kW}$. The commercial systems studied here range from about 1 to $3 \mathrm{MW}$, which is in line with systems operating in the market today. Table 4 details the NG microturbine assumptions applied in this analysis.

Lastly, the size of NG microturbines, which is dependent upon each case study's load profile, largely drives upfront capital costs. This analysis uses the maximum hourly load, a $10 \%$ reserve requirement, and the above assumed efficiency rates for sizing microturbines for each scenario. Since we assume that the DG system for the NG-RE hybrid case and the NG-only case will fully meet load, the maximum hourly demand (including both electric and non-electric) is calculated once the hourly solar PV output simulations are conducted and accounted for in meeting demand, and the NG microturbine size is determined by this hourly residual electricity demand and non-electric NG demand combined, plus the $10 \%$ reserve requirement. ${ }^{17}$

\subsection{Utility Rate Structures}

Utility-specific electricity rate structures based upon upon location determine the avoided payments (i.e., savings) to local utilities included as cash inflows. Since retail rates are relatively fixed for end-use customers, rates are escalated by $2 \%$ annually. For the case of Suffolk County, NY, the assumed project location is within the PSEG Long Island territory for electricity and the National Grid territory for NG. Public and transparent price data from these utilities allowed for consideration of both standard and TOU rate structures, special

\footnotetext{
${ }^{17}$ It is possible that smaller systems are less efficient, but we do not have any data on such systems. Our derivation for the system size requirement is a very crude estimate. We add hourly non-electric NG demand (kWh) to residual hourly electricity demand determine hourly demand for NG in $\mathrm{kWh}$ terms. We find the maximum $\mathrm{kWh}$ gas demand in an hour over the system lifetime and add a $10 \%$ reserve requirement to determine the maximum hourly kWh microturbine capacity. We apply an $80 \%$ global efficiency to determine the required microturbine size for meeting maximum hourly load plus reserve. This makes our sizing of the microturbines "choppy".
} 
distributed generation rates (for both NG microturbines and RE), and net metering, which enables detailed hourly calculations as well as incurred costs from operating the new onsite DG system. The historical utility-specific NG retail rates were used in projections as described in Section 4.

For the case of Waco, TX, the projects are assumed to operate within the TXU Energy service area, which is in the Oncor Electric Delivery service area. Multiple rate plan options exist, including those applicable for DG systems and alternative structures that are determined by time of use. For instance, TXU offers a fixed rate plan (defined as "standard" in this analysis), a free nights option for residential customers (defined as TOU here), and an alternative rate structure for businesses as well where the price is reduced by $50 \%$ during certain hours of operation. Appendix A details the rate structures. Since utilityspecific NG retail rates were unavailable for Waco, Texas' statewide historical residential monthly average NG prices were used for estimating NG price projections following the procedures described in Section 4 .

\subsection{Additional Financial Model Assumptions}

Location-specific incentive payments and tax liabilities, and the federal Investment Tax Credit (ITC) of 30\% for the RE systems, O\&M and replacement costs and loan principal and interest payments are also incorporated into the valuations.

Additional cash outflows for residential solar PV include a total installed cost per Wdc of $\$ 3.70$, fixed $0 \& \mathrm{M}$ of $\$ 36 / \mathrm{kW}$-year, and a fixed (annual) 0\&M cost of $\$ 15 /$ year. ${ }^{18}$ For commercial systems, a totaled installed cost of $\$ 2.60 / \mathrm{Wdc}$ and a fixed O\&M of $\$ 20.00 / \mathrm{kW}$ year are assumed. Microturbine capital cost estimates in the industry currently range from $\$ 700$ per $\mathrm{kW}$ to $\$ 1,100$ per $\mathrm{kW}$ and an additional $\$ 75$ to $\$ 350$ per $\mathrm{kW}$ for $\mathrm{CHP}$, and installation costs are generally around $30 \%$ to $50 \%$ of total upfront outlay (Capehart, 2014).

\footnotetext{
${ }^{18}$ All per unit cost assumptions for the RE components follow the default assumptions from the National Renewable Energy
} Laboratory's (NREL) System Advisor Model (SAM) (SAM, 2014). 
The following microturbine cost assumptions are applied: $\$ 700$ per $\mathrm{kW}$ capital cost, $\$ 0.003$ per $\mathrm{kWh}$ non-fuel $0 \& \mathrm{M}$ cost, $\$ 100$ per $\mathrm{kW}$ for adding CHP to the system, and installation costs of $30 \%$ of capital costs. Insurance incurs $1 \%$ of inflation-adjusted total installed costs for commercial systems, and there is no insurance cost for residential systems.

Financial model assumptions for NPV calculations follow those outlined in the National Renewable Energy Laboratory's (NREL) System Advisor Model (SAM) documentation (SAM, 2014), which are based on the definitions and methods described in Short et al (1995). Cash flows for 25-year and 30-year project lifetimes and loan terms are considered for the residential and commercial applications, respectively. Debt ratio assumptions are $50 \%$ and $100 \%$ for the commercial and residential applications, respectively. Loan principal and interest payments, and tax liabilities, are included under the assumption of a mortgage financing structure for the residential systems, and the commercial financing structure does not consider a power purchase agreement (PPA) structure. Table 5 summarizes all financing assumptions.

\section{Results}

Considering both the DCF and ROA valuations, our findings consistently suggest that the hybrid NG-RE systems are more attractive than their single-technology comparable alternatives, even without incentives for the solar component (the federal ITC and statelevel financial incentives) in some cases. Furthermore, all DG systems are economically favorable relative to BAU. Since the BAU cash flows include the combined cost of electricity and heating without DG offsetting any load, this finding indicates that, when discounted over the project lifetime, the savings on utility bills from installing DG (regardless of configuration design) are higher than the incurred costs investing in the system consistently 
across configurations, in the long run. The DG investments become even more economically favorable under TOU electricity rate structures and net metering across all cases.

The findings for the residential application in Suffolk County, NY under the baseline NG price volatility scenario and a high NG price volatility scenario across system configurations and electricity rate structures are presented in Table 6 and Table 7, respectively. Valuation results are presented in nominal dollars, and negative values are shown in parentheses and red text. The initial investment outlay required for each configuration is also included. Note investment outlays are the largest for NG-only configurations because of system size requirements, which are determined by the microturbine's global efficiency. When only NG is used, the onsite microturbines account for $100 \%$ of both heating and electricity demands, and so the system is sized accordingly. On the other hand, when solar is included, enough electricity demand is offset to reduce the size of the NG microturbine required in order to still meet $100 \%$ of residual electricity and heating demands, which translates into lower upfront capital costs. This reduction in capital costs is larger in magnitude than the additional cost of installing solar for systems located in Suffolk County, NY, mostly because of the high NG demand for heating. For Waco, TX, where there is no NG demand for heating, the value proposition of the hybrid system relative to NG-only is not as favorable (see Appendix C).

Two variations of RE-only are shown-one including the negative cash flows of nonelectric NG load accounted for by the local utility, and one including only cash flows for electricity demand (non-electric NG payments to the utility aren't included as cash outflows, so only the electricity components are considered). Investment decisions between one system and another, or between DG systems relative to BAU, can be made based on the highest (or least negative) NPV and ROV values. When comparing investment options, more (less) positive (negative) NPV or ROV values represent the more economically attractive 
investment. In other words, a negative NPV or ROV doesn't necessarily mean that the investment shouldn't be pursued if the value is in fact less negative than the BAU case. The less negative the NPV, the more savings achieved relative to BAU.

For this application, NPVs and ROVs are positive for the hybrid NG-RE system, even without financial incentives for the solar component and under high NG price volatility. Alternatively, the NG-only and RE-only configurations produce negative NPVs and ROVs, however investing in either single-technology DG system is still more economically attractive than BAU. For instance, note that the figures for the RE-only cases are low because they include cash outflows for residual electricity demand, however the figures are less negative than those for BAU, suggesting savings from investing in a RE-only system. As expected, the investment is even more attractive when incentives for solar are available, however they aren't required for the investment to payoff relative to BAU. Under standard electricity rates and without incentives for solar, the hybrid NG-RE investment would take 14.46 years to payoff (or 6.45 years with incentives). These figures are 12.6 and 4.27, respectively, under a TOU electricity rate structure and when net metering is available.

Similarly, for the case of a hospital located in Suffolk County, NY, the hybrid NG-RE systems consistently produce positive NPVs and ROVs (and generally more favorable outcomes than the single technology alternatives), and the payback periods are much lower than the residential applications given the scale of the investment (see Table 8 and Table 9). Investing in a hybrid NG-RE system pays off in 4.98 years without incentives (3.25 years with incentives) under a standard electricity rate structure, and respectively, 4.54 years without incentives (and 2.96 years with incentives) under TOU rates and net metering. On the other hand, while the hybrid NG-RE systems are more attractive than their singletechnology alternatives with solar incentives, the NG-only system is more attractive when incentives are unavailable. Again, all DG systems are economically favorable relative to BAU, 
and the same patterns comparing the findings under high NG price volatility relative to low NG price volatility unfold.

Appendix C presents the findings for the applications based in Waco, TX. Consistent results and patterns emerge, however the findings generally do not favor hybrid systems as strongly. This is mostly because of the low non-electric NG load in Texas compared to the high NG load meeting heating needs in regions such as New York, In other words, investments in DG systems including NG microturbine components become more attractive when NG demand is higher because the customer avoids significantly higher NG payments to local utilities. The systems still offer scale economies, however, and the payoff is more attractive for commercial systems even with lower non-electric NG demand.

\section{Conclusion and Policy Implications}

Although recent work provides anecdotal evidence of NG-RE synergies in the power sector, this paper is the first to our knowledge to explore project-level business case studies to quantify and compare the value of investing in hybrid NG-RE, NG-only, and RE-only systems in commercial and residential applications, as well as the business-as-usual case of not installing a DG system at all. By modeling system economics at the hourly level and with location-specific data and assumptions, the methodology implemented allowed for consideration of technology performance and operational risk profiles, inherently capturing the uncertainties that characterize NG and VRE. Furthermore, as both DCF and ROA rely on present value calculations of annual cash flows, detailed hourly-level cost and revenue streams were incorporated, such as utility-specific avoided electricity and natural gas utility bill payments, incentives, tax benefits and liabilities, capital costs, variable 0\&M costs, and loan principal and interest payments. 
The findings consistently suggest that hybrid distributed NG-RE systems for the residential and commercial building applications studied here are more favorable investments relative to their single-technology alternatives when direct financial incentives for solar PV are present. In some cases, NG-only systems are favored over hybrid systems when incentives for solar are not available. All DG systems are found to be more economically attractive compared to BAU. Overall, DG investments are more attractive under TOU electricity rate structures and when net metering is available. These results hold true when using both NPV and ROA valuation metrics.

These results highlight the importance of creating an enabling policy environment that is conducive to the deployment of such hybrid systems in distributed applications, given the value that they can bring to consumers relative to BAU or their single-technology alternatives. In addition, quantifying the value of such investments at the project level can help inform public investments that aim to accelerate clean energy technology adoption.

Furthermore, given the importance of both NG and RE for reducing greenhouse gas emissions associated with the power sector, our findings provide insights into the value of NG and RE being used as complements as opposed to substitutes when considering promoting the adoption of lower greenhouse gas emitting energy technologies. Viewing NG and RE as complements could motivate joint research platforms for investigating policy and market structure options that are mutually beneficial to both the NG and RE communities, as more analysis and dialogue is needed for developing integrated action plans. While partnerships between the two industries historically have been uncommon, there are many opportunities for developing such partnerships to create integrated research and information exchange. Policymakers can use the collaborative analysis and dialogue outcomes to design complementary energy policies towards de-carbonization objectives. 
Consistency between the NPV and ROA results provides robustness in the findings, but perhaps more importantly, ROA provides additional confidence in the results when comparing investment alternatives because it considers the irreversible and uncertain nature of electricity generation technology investments. When cash flows are uncertain, as experienced in the power sector, assuming they are deterministic and static can be costly. In reality, several underlying uncertain and sometimes volatile attributes related to system operations, efficiency, and input prices impact the value of power generation technologies, and ROA derived from an analysis of operations at the hourly level, as done here, accounts for these.

Lastly, the findings highlight the importance of policy for determining payoff, which has implications for considering mechanisms aiming to increase deployment of hybrid NGRE distributed systems. Consider, for example, the residential application in Suffolk County facing baseline NG price volatility. Under a TOU rate structure and net metering, the hybrid system's NPV to investment ratio implies a $9.6 \%$ return with no incentives and $36 \%$ with incentives. For the commercial system, these figures are $122 \%$ and $147 \%$, respectively. One could also consider the NPV to investment ratio to the utility or to government sectors, suggesting that when certain conditions align, these can be win-win policies.

There are numerous pathways forward for continued work in this area. For example, the case studies explored here did not consider the potential for storage, a promising DG technology, nor did it include non-market costs and benefits associated with investing in a DG system for stand-alone applications. Quantifying features such as reliability benefits and ancillary services would further enhance the economic attractiveness of these investments. Additionally, as demonstrated by the scaling-up of systems from a residential to commercial application, DG investments offer economies of scale. Pursuing valuation analyses of microgrid applications and community power 
configurations remains ripe for future research. Lastly, these valuations quantified the investment value from the system owner's perspective, but inclusion of the benefits and costs to other market agents would allow for understanding total welfare impacts on the wider system as a whole. 
Acknowledgments: The Joint Institute for Strategic Energy Analysis is operated by the Alliance for Sustainable Energy, LLC, on behalf of the U.S. Department of Energy's National Renewable Energy Laboratory, the University of Colorado-Boulder, the Colorado School of Mines, the Colorado State University, the Massachusetts Institute of Technology, and Stanford University. This analysis was prepared under Contract No. DE-AC36-08G028308 and Task No. WWJI1022. The authors would like to thank the following expert reviewers for their comments and suggestions: Saurin Shah of Neuberger Berman, Matt Ferguson of Kilpatrick Townsend \& Stockton, one anonymous expert commenter, and two anonymous referees. The authors also would like to thank the participants of the Synergies of Natural Gas and Renewable Energy: 360 Degrees of Opportunity workshop series for their expertise and helping to inform this study, and particularly those who participated in the San Antonio, Texas Edition workshop in November 2014 for their invaluable feedback and comments on preliminary analyses. 


\section{References}

Abadie LM., Chamorro JM., 2009. Monte Carlo valuation of natural gas investments, Review of Financial Economics 18 (10-22).

Awerbuch S., 1993. The surprising role of risk in utility integrated resource planning, The Electricity Journal, 6(3), p. 20-33.

Awerbuch S., 1996. Capital budgeting, technological innovation and the emerging competitive environment of the electric power industry, Energy Policy, 24(2), p. 195-202.

Awerbuch S., 2000a. Getting it right: the real cost impacts of a renewables portfolio standard, Public Utilities Fortnightly 15.

Awerbuch S., 2000b. Investing in photovoltaics: Risk, accounting, and the value of new technology, Energy Policy 28, 1023-1035.

Awerbuch S., 2004. "Portfolio-Based Electricity Generation Planning: Implications for Renewables and Energy Security," Report for REEP/UNEP, London; Paris.

Awerbuch S., 2007. Efficient electricity generating portfolios for Europe: maximizing energy security and climate change mitigation, EIB Papers 7/2007, European Investment Bank.

Asano H., Ariki W., Bando S., 2010. "Value of investment in a microgrid under uncertainty in the fuel price," Power and Energy Society General Meeting, 2010 IEEE, available at: http://ieeexplore.ieee.org/xpl/articleDetails.jsp?arnumber=5589804.

Baker MP., Mayfield ES., Parsons JE., 1998. Alternative Models of Uncertain Commodity Prices for Use with Modern Asset Pricing Methods, The Energy Journal, 19(1): 115-148.

Blanco C., Soronow D., 2001. "Mean Reverting Processes-Energy Price Processes Used for Derivatives Pricing \& Risk Management", Energy Pricing, Commodities Now, June 2001. Available at: http://www.fea.com/resources/a mean reverting processes.pdf.

Bolinger M., Wiser R., Golove WH., 2002. Quantifying the Value that Wind Power Provides as a Hedge Against Volatile Natural Gas Prices, LBNL, available at: http://emp.lbl.gov/publications/quantifyingvalue-wind-power-provides-hedge-against-volatile-natural-gas-prices.

Bush B., Jenkin T., Lipowicz D., Arent DJ., 2012. Variance Analysis of Wind and Natural Gas Generation under Different Market Structures: Some Observations, NREL/TP-6A20-52790, Golden, CO: National Renewable Energy Laboratory.

Capehart BL., 2014. "Microturbines," Whole Building Design Guide, a program of the National Institute of Building Available at: http://www.wbdg.org/resources/microturbines.php?r=office.

Cochran J., Zinaman 0., Logan J., Arent D., 2014. Exploring the Potential Business Case for Synergies Between Natural Gas and Renewable Energy. National Renewable Energy Laboratory Technical Report NREL/TP-6A50-60052, Golden, CO: NREL.

Copeland T., Antikarov V., 2001. Real Options: A Practitioner's Guide, New York, NY: TEXERE.

Damodaran A., 2012. "Valuation: Packet 3 Real Options, Acquisition Valuation and Value Enhancement," available at http://people.stern.nyu.edu/adamodar/pdfiles/eqnotes/packet3a.pdf. 
Davis GA, Owens B., 2003. Optimizing the level of renewable electric R\&D expenditures using real options analysis, Energy Policy.

Deng S.J., Johnson B., Sogomonian A., 2001. Exotic electricity options and the valuation of electricity generation and transmission assets, Decision Support Systems, (30) 3, 383-392.

Dixit A., Pindyck R., 1994. Investment under Uncertainty, New Jersey: Princeton University Press.

Environmental Protection Agency (EPA), 2008. Technology Characterization: Microturbines. Prepared by Energy and Environmental Analysis, an ICF International Company. Available at: http://www.epa.gov/chp/documents/catalog chptech microturbines.pdf.

Fernandes B., Cunha J., Ferreira P., 2011. The use of real options approach in energy sector investments, Renewable and Sustainable Energy Reviews, 15; p. 4491-4497.

Gillette S., 2010. Microturbine Technology Matures, POWER Magazine, available at: http://www.powermag.com/microturbine-technology-matures/.

Gjolberg 0., Guttormsen AG., 2002. Real options in the forest: What if prices are mean-reverting? Forest Policy and Economics 4, pp. 13-20.

Gotham D.J., Nderitu D.G., Giraldo J.S., Preckel P.V., 2013. Natural Gas Market Study, State Utility

Forecasting Group, Indiana, available at:

http://www.in.gov/iurc/files/Natural Gas Market Study.pdf.

He Y., 2007. Real Options in the Energy Markets. Dissertation to obtain doctor's degree at the University of Twente on Friday 05, October 2007. http://doc.utwente.nl/58482/1/thesis He.pdf.

Hendron R., Engebrecht C., 2010. Building America House Simulation Protocols, National Renewable Energy Laboratory, Golden, CO. Available at: http://www.nrel.gov/docs/fy11osti/49246.pdf.

Insley M., Chen S., 2012. Regime switching in stochastic models of commodity prices: An application to an optimal tree harvesting problem. Journal of Economic Dynamics and Control 36(2), pp. 201-219.

Insely M., Rollins K., 2005. On solving the multirotational timber harvesting problem with stochastic prices: A linear complementarity formulation, American Journal of Agricultural Economics 87(3), pp. 735-755.

Jenkin T., Diakov V., Drury E., Bush B., Denholm P., Milford J., Arent D., Margolis R., Byrne R., "The Use of Solar and Wind as a Physical Hedge against Price Variability within a Generation Portfolio," NREL/TP-6A20-59065, Golden, Colorado: National Renewable Energy Laboratory.

Kienzle F., Andersson G., 2009. Valuing Investments in Multi-Energy Generation Plants under Uncertainty: A Real Options Analysis, ETH Zurich, available at: https://www.eeh.ee.ethz.ch/uploads/tx ethpublications/kienzle iaee vienna sept 09.pdf.

Kjaerland F., 2009. Valuation of Generation Assets-a Real Options Approach, Doctoral thesis submitted to the Bodo Graduate School of Business for the degree of Ph.D.

Lee A., Zinaman O., Logan J., 2012. Opportunities for Synergy Between Natural Gas and Renewable Energy in the Electric Power and Transportation Sectors, National Renewable Energy Laboratory Technical Report NREL/TP-6A50-56324, Golden, CO: NREL.

OpenEI, 2013. Commercial and Residential Hourly Load Profiles for all TMY3 Locations in the United States. Last accessed August 2014. Available at: http://en.openei.org/datasets/node/961. 
Myers SC., 1984. “Finance Theory and Financial Strategy,", Interfaces, Vol. 14, No. 1, pp. 126-137.

Parsons C., 2011. Quantifying Natural Gas Storage Optionality: A Two-Factor Tree Model, WTM Energy Software, LLC., Available at: http://www.wtmenergy.com/pdf/soswhitepaper.pdf.

Pindyck RS., 1999. The long-run evolution of energy prices, The Energy Journal, 20(2).

Pindyck RS., 2008. "Lectures on Real Options: Part I - Basic Concepts," Massachusetts Institute of Technology, available at:

http://web.mit.edu/rpindyck/www/Courses/RO P1 Handout\%20Slides.pdf.

Pless J., Arent D., Logan J., Cochran J., Zinaman O., Stark C., forthcoming. Exploring Transitions to a Sustainable Energy Future: Lessons from Regional Stakeholder Workshops on the Potential Synergies of Natural Gas and Renewable Energy, Golden, CO: Joint Institute for Strategic Energy Analysis.

REC Solar, 2014. "Evaluating Commercial Solar: Payback, ROI, NPV, and IRR, July 20, 2014". Available at: http://blog.recsolar.com/2014/07/evaluating-commercial-solar-payback-roi-npv-and-irr/

Reiner D., Chyong K., Ralph D., n.d. Discounted Cash Flow and Options Thinking Approaches Applied to Green Energy Investment-The Case of CCS.

SAM, 2014. System Advisory Model, Financial Model Documentation, last accessed October 2014. Available at: https://sam.nrel.gov/financial.

Santos L., Soares I., Mendes C., Ferreira P., 2014. Real options versus traditional methods to assess renewable energy projects. Renewable Energy, 68; 588-594.

Schwartz ES., 1997. The Stochastic Behavior of Commodity Prices: Implications for Valuation and Hedging, The Journal of Finance 52(3); 923-973.

Short W., Packey D., Holt T., 1995. A Manual for the Economic Evaluation of Energy Efficiency and Renewable Energy Technologies, National Renewable Energy Laboratory, NREL/TP-462-5173, Golden, CO: NREL.

Sick G., 1995. Real options, Handbooks in operations research and management science, Vol. 9 (p. 631 691), Elsevier Science.

Siddiqui AS., Marnay C., 2008. "Distributed Generation Investment by a Microgrid under Uncertainty, Lawrence Berkeley National Laboratory, Report Number LBNL-872E.

Siddiqui AS, Marnay C., Wiser RH, 2007. Real options valuation of US federal renewable energy research, development, demonstration, and deployment, Energy Policy.

SunPower Corporation, 2012. Solar Valuation: An Appraiser's Guide to Solar, available at http://us.sunpower.com/sites/sunpower/files/media-library/white-papers/wp-residential-realestate-appraisers-guide-accurately-valuate-residential-rooftop-solar-electric-pv.pdf.

Swishchuck AV., 2008. Explicit Option Pricing Formula for a Mean-Reverting Asset in Energy Market, Journal of Numerical and Applied Mathematics, 1(96): p. 216-233.

Szolgayova J., Fuss S., Obersteiner M., 2008. Assessing the effects of $\mathrm{CO} 2$ price caps on electricity investments-a real options analysis, Energy Policy. 
Trigeorgis L., 1996. Real options-Managerial flexibility and strategy in resource allocation. The MIT Press. 


\section{Appendix A: Utility Rate Structure Assumptions}

\section{A1. Suffolk, NY Utility Rate Structures}

The following utility-specific rate structures are implemented in electricity bill calculations (avoided costs) as well as for the costs incurred for operating the distributed generation systems. In all cases, the utility defined peak hours as weekdays from 10:00am to $8: 00 \mathrm{pm}$ and all day on the weekends, and rates were updated as of April 1, 2014.

Standard Residential Rate Structure (PSEG Long Island Rate 180)

* Fixed service charge of $\$ 0.36$ per day

* First 250 kWh (per kWh):

- June 1 through September 30: $\$ 0.0904$

- October 1 through May 31: $\$ 0.0904$

* Demand in excess of $250 \mathrm{kWh}$ (per kWh):

- June 1 through September 30: $\$ 0.1022$

- $\quad$ October 1 through May 31: $\$ 0.0834$

Standard Commercial General Use Rate Structure (PSEG Long Island Rate 280)

* Fixed daily service charge of $\$ 0.36$ per day

* Energy charge (per kWh)

- June 1 through September 30: \$0.1099

- $\quad$ October 1 through May 31: $\$ 0.0910$

Time-of-Use Residential Rate Structure (PSEG Long Island Rate 188)

* Fixed service charge of $\$ 0.36$ per day

* Daily meter charge: $\$ 0.10$

* Offpeak (per kWh):

- June 1 through September 30: $\$ 0.0625$ 
- $\quad$ October 1 through May 31: $\$ 0.0484$

* Peak (per kWh)

- June 1 through September 30: $\$ 0.2782$

- $\quad$ October 1 through May 31: $\$ 0.0935$

Time-of-Use Commercial Rate Structure (PSEG Long Island Rate 288)

* Fixed service charge of $\$ 0.36$ per day

* Daily meter charge: $\$ 0.10$

* Offpeak (per kWh)

- June 1 through September 30: $\$ 0.625$

- $\quad$ October 1 through May 31: $\$ 0.0484$

* Peak (per kWh)

- June 1 through September 30: \$0.2782

- $\quad$ October 1 through May 31: $\$ 0.0935$

National Grid Natural Gas Rate Structure for Non-Distributed Generation Residential Customers (SC1 rate classification)

* Delivery and service charges:

- Basic service charge and first three Therms (or less): $\$ 20.35$

- Next 47 Therms: $\$ 0.36247$ per Therm

- $\quad$ Over 50 Therms: $\$ 0.06385$ per Therm

* Other charges:

- $\quad$ Fixed MTA surcharge: $\$ 0.15$

- $\quad$ Sales tax: $4 \%$

* Supply charges

- Vary monthly and determined by market. See natural gas price modeling section. 
National Grid Natural Gas Rate Structure for Distributed Generation Residential Customers

(SC13)

* Service is firm sales based on monthly consumption

* Delivery and service charges:

- Basic service charge and first three Therms (or less): $\$ 27.46$

- Over three Therms: \$0.03914 per Therm

* Supply charges

- Vary monthly and determined by market. See natural gas price modeling section.

National Grid Natural Gas Rate Structure for Non-Distributed Generation Commercial Customers (SC2 rate classification)

* Delivery and service charges:

- Basic service charge and first three Therms (or less): $\$ 24.17$

- $\quad$ Next 277 Therms: $\$ 0.36247$ per Therm

- Next 4,720 Therms: $\$ 0.16985$ per Therm

- $\quad$ Over 5,000 Therms: $\$ 0.05445$

* Other charges:

- $\quad$ Fixed MTA surcharge: $\$ 0.15$

- Sales tax: $4 \%$

* Supply charges

- Vary monthly and determined by market. See natural gas price modeling section.

National Grid Natural Gas Rate Structure for Distributed Generation Commercial Customers (SC12) for Annual Consumption of 250,000 Therms to 1,000,000 Therms

* Service is firm sales based on monthly consumption

* Delivery and service charges:

- Basic service charge and first three Therms (or less): $\$ 466.49$

- Over three Therms (April to October): $\$ 0.04522$ per Therm 
- Over three Therms (November to March): $\$ 0.05728$ per Therm

* Supply charges

- Vary monthly and determined by market. See natural gas price modeling section.

\section{A2. Waco, TX Electric Utility Rate Structures}

The following utility rate structures are assumed for the Waco, TX cases.

\section{Standard Residential Rate Structure (TXU Energy, Oncor Electric Delivery Service Area)}

TXU energy pays 7.5 cents per kWh for surplus generation from solar and 6 cents per kWh from nonsolar. This is provided as a bill credit for surplus, quarterly. A gross receipts tax is imposed on each retail electric provider operating in an incorporated city or town with a population greater than 1,000 , ranging from $0.581 \%$ to $1.997 \%$. This analysis applies a $1 \%$ tax.

The TXU Energy Texas Choice fixed rate plan is as follows:

- $\$ 4.95$ monthly base charge

- 8.1 cents per kWh

- Oncor electric delivery charges

\section{Standard Commercial Rate Structure (TXU Energy, Oncor Electric Delivery Service Area)}

- Simple, flat, non-seasonal energy charge per kWh as well as a monthly base charge and Transmission and Distribution Utility (TDU) delivery charges.

- Base charge: $\$ 7.90$ per month

- Energy charge: 8.2 cents per kWh

- Oncor electric delivery charges

Alternative Residential Rate Structure (TXU Energy Free Nights, Oncor Electric Delivery Service Area) 
- TXU Energy offers 'free nights', where energy charges are free from 9:00pm to 6:00am every day. The base charge, TDU delivery charges, state and local taxes, and other billed charges are applied normally. A simple rate for energy during daytime hours is then applied.

- $\quad$ Base charge: $\$ 9.95$

- $\quad$ Energy charge (per kWh): 14.7 cents per kWh (for Waco)

- $\quad$ TDU delivery charges

\section{Alternative Commercial Rate Structure (TXU Energy, Oncor Electric Delivery Service Area)}

- A discount can be applied to energy charges in the mornings from 6:00am to 2:00pm, and then the standard rate is applied the remainder of the day. This allows for morning energy to be charged at 5.9 cents per $\mathrm{kWh}$ and the rate is 11.8 cents per $\mathrm{kWh}$ otherwise.

- $\$ 9.95$ base monthly charge

\section{TDU Delivery Charges for Oncor Service Area}

- Total per month base charge: $\$ 5.25$

- Monthly charges: $\$ 0.78$ customer charge, $\$ 2.28$ metering charge, and $\$ 2.19$ advanced metering cost recovery factor (if net metering)

- Charges on a per kWh basis: $\$ 0$ transmission system charge, $\$ 0.018583$ distribution system charge, $\$ 0.000169$ nuclear decommissioning fee, $\$ 0.012012$ transmission cost recovery factor, $\$ 0.000522$ transition charge TC1, $\$ 0.000806$ transition charge TC2, rate case expense surcharge 2 (RCE) $\$ 0.000033$, rate case charge (RCE-R) of $\$ 0.000050$. 


\section{Appendix B: Natural Gas Demand Unit Conversions}

The amount of fuel used per kWh is equal to the heat rate (Btu per kWh) divided by the fuel heat content (Btu per physical unit). As such, the volume of gas per kWh in terms of 1,000 cubic feet (mcf) of natural gas can be calculated as

$$
M c f \text { per } k W h=\left(\frac{H R_{B t u / k W h}}{F C_{B t u / m c f}}\right) * 1000
$$

where $H R_{B t u / k W h}$ is the heat rate and $F C_{B t u / m c f}$ is the fuel heat content. The final conversion into Therms can be calculated as

$$
D_{\text {therms }}=D_{k W h} *\left(\frac{m c f}{k W h}\right) *\left(\frac{\text { therms }}{M c f}\right)
$$

where $D_{\text {therms }}$ is demand for gas in Therms, $D_{k W h}$ is the demand for gas in $\mathrm{kWh}$, and Therms per mcf is determined by system efficiency. 


\section{Appendix C: Results from Waco, TX Case Study Valuations}

Tables A1 and A2 provide the single home and critical services building DCF and ROA valuation results for the case studies assumed to be located in Waco, TX. Note that the REonly cases presented here are slightly different—because there is no NG demand for heating in the load profiles for Waco, TX, the RE-only case does not include non-electric NG utility bills as additional cash outflows. For the Suffolk County, NY configurations, two different RE-only cases were considered: one in which NG utility bills for heating were included as cash outflows and another where the cash flows included electricity only. Again, the findings here suggest that the RE-only systems are less favorable than the NG-only and hybrid RE-NG systems but more favorable than BAU.

There are two key reasons for why the hybrid NG-RE hybrid systems are found to be less favorable in Waco, TX than in Suffolk County, NY. First, NG demand for heating is significantly higher in New York, which translates into a higher savings incurred from installing a DG system that accounts for this demand. Second, given the load profiles and solar output simulations for Waco, there is an inability to scale down the NG microturbine size and thus reduce upfront capital costs. Although counter to what is known about solar PV potential on average in Texas relative to New York, the PVWatts simulations produce an hourly solar output profile for Waco that does not offset electricity demand as much as the hourly solar output profile for Suffolk County offsets electricity demand. Overall, this means less electricity load is offset by the solar system in the Waco cases. Without enough electricity load offset, the NG microturbine size requirement for meeting residual demand does not decrease in the hybrid NG-RE case relative to the NG-only case. If the PVWatts simulations matched the hourly load profile in a way that offset more electricity demand, then the microturbine in the hybrid cases could be scaled down accordingly and the owner would incur lower upfront capital costs for the hybrid NG-RE systems. This requires further 
investigation related to the PVWatts solar output simulations as well as the demand profile simulations. 


\section{Quantifying the Value of Investing in Distributed Natural Gas and Renewable Electricity Systems as Complements: Applications of Discounted Cash Flow and Real Options Analysis with Stochastic Inputs}

By Jacquelyn Pless, a,b Douglas J. Arent,a Jeffrey Logan,c Jaquelin Cochran, c and Owen Zinamanc

June 15, 2016

a Joint Institute for Strategic Energy Analysis (JISEA) at the National Renewable Energy Laboratory (NREL), 15013 Denver W Parkway, Golden, CO 80401

${ }^{b}$ Colorado School of Mines, 816 15th Street, Engineering Hall, Golden, CO 80401

c National Renewable Energy Laboratory (NREL), 15013 Denver W Parkway, Golden, CO 80401

\section{Corresponding author:}

Jacquelyn Pless, Colorado School of Mines

$81615^{\text {th }}$ Street, Engineering Hall

Golden, CO 80401

jacq.pless@gmail.com

Phone: 802-825-1068

\section{TABLES ONLY}

Table 1: Cash Flows Used in this Analysis for Each Configuration

\begin{tabular}{lll}
\hline \hline & \multicolumn{1}{c}{ Cash Inflows } & \multicolumn{1}{c}{ Cash Outflows } \\
\hline BAU & & $\begin{array}{l}\text { Electricity utility bills } \\
\text { Natural gas utility bills }\end{array}$ \\
\hline RE-only & Electricity bill savings (offset partially) & \multicolumn{1}{c}{$\begin{array}{l}\text { Initial investment outlay } \\
\text { Installation costs }\end{array}$} \\
& Net metering revenues (if applicable) & Electricity utility bills for residual demand \\
& Incentive payments & Natural gas utility bills (non-electric heating) \\
& & Loan principal and interest payments \\
& & Fixed O\&M and inverter replacement costs \\
& & Tax liabilities \\
\hline NG-only & Electricity utility bill savings (offset 100\%) & Insurance \\
& Non-electric natural gas utility bill savings (offset 100\%) & Initial investment outlay \\
& & Installation costs \\
& & Loan principal and interest payments \\
& & Variable O\&M costs (fuel costs) \\
& & Fixed O\&M costs \\
& & Tax liabilities \\
& & Insurance \\
\hline Hybrid NG-RE & Electricity utility bill savings (offset 100\%) & Initial investment outlay \\
& Non-electric NG bill savings (offset 100\%) & Installation costs \\
& Net metering revenues (if applicable) & Loan principal and interest payments \\
& Incentive payments & Fixed O\&M costs for both NG and RE systems \\
& & Variable O\&M costs (fuel costs) \\
& & Tax liabilities \\
& & Insurance \\
\hline \hline
\end{tabular}


Table 2: Analogy of a call option relative to project characteristics (Source: Partially derived from Fernandes et al., 2011)

\begin{tabular}{ll} 
Project Characteristics & Call Option \\
\hline Present value of positive cash inflows & Value of underlying asset \\
Present value of negative cash outlays & Strike price \\
Length of deferral time & Time to maturity \\
Time value of money & Risk-free rate \\
Volatility of project's returns & Variance of stock returns \\
\hline
\end{tabular}

Table 3: System design descriptions and operating assumptions

\begin{tabular}{ll}
\hline System design & Description \\
\hline BAU & No onsite system. Electricity and NG purchased from local utility as usual. \\
RE-only & $\begin{array}{l}\text { Onsite RE system installed and output is consumed hourly as produced, which } \\
\text { offsets some electricity demand. Residual electricity demand is purchased from local } \\
\text { utility. Non-electric NG demand (for heating) is purchased from local utility, as per }\end{array}$ \\
& $\begin{array}{l}\text { usual. } \\
\text { Onsite NG system installed that accounts for 100\% of both electricity and non- } \\
\text { NG-only }\end{array}$ \\
electric (heating) NG demand. \\
Bybrid NG-RE \\
$\begin{array}{l}\text { Both NG and RE systems are installed. Onsite RE offsets some electricity demand. } \\
\text { Onsite NG meets residual electricity demand plus non-electric (heating) NG demand. }\end{array}$ \\
\hline
\end{tabular}

Table 4: NG microturbine performance assumptions

\begin{tabular}{lcc}
\hline & Residential Applications & Commercial Applications \\
\hline Global efficiency ${ }^{1}$ & $80 \%$ with CHP & $80 \%$ with CHP \\
Heat rate (more efficient systems have & & \\
lower heat rates) & $13,000 \mathrm{Btu} / \mathrm{kWh}$ & $12,000 \mathrm{Btu} / \mathrm{kWh}$ \\
Fuel heat content & $1,050 \mathrm{Btu} / \mathrm{scf}$ & $900 \mathrm{Btu} / \mathrm{scf}$ \\
\hline
\end{tabular}

Table 5: Financial Model Assumptions

\begin{tabular}{lcc}
\hline \hline & $\begin{array}{c}\text { Residential } \\
\text { (mortgage financed) }\end{array}$ & Commercial \\
\hline Analysis period (years) & 25 & 30 \\
Inflation rate & $2.50 \%$ & $2.50 \%$ \\
Real discount rate & $5.50 \%$ & $5.50 \%$ \\
Nominal discount rate & $8.14 \%$ & $8.14 \%$ \\
Loan (debt) percent & $100 \%$ & $50 \%$ \\
Loan term (years) & 25 & 30 \\
Loan interest rate & $6 \%$ & $6 \%$ \\
Depreciation & $\mathrm{N} / \mathrm{A}$ & MACRS (Mid Quarter) \\
\hline \hline
\end{tabular}

Table 6. DCF and ROA Valuations for a Single Home DG System Located in Suffolk County, New York (baseline NG price volatility) (nominal dollars)

\begin{tabular}{|c|c|c|c|c|c|c|c|c|}
\hline System Design & BAU & NG-Only & Solar+Gas & BAU & NG-Only & $\begin{array}{l}\text { RE-Only } \\
\text { (heating } \\
\text { included) }\end{array}$ & $\begin{array}{l}\text { RE-Only } \\
\text { (electricity } \\
\text { only) }\end{array}$ & Solar+Gas \\
\hline Electricity Rates & Standard & Standard & Standard & TOU & TOU & TOU & TOU & TOU \\
\hline
\end{tabular}

${ }^{1}$ See Footnote 17 for discussion about this assumption and its implications. 


\begin{tabular}{|c|c|c|c|c|c|c|c|c|}
\hline Net Metering & No & No & No & Yes & Yes & Yes & Yes & Yes \\
\hline $\begin{array}{l}\text { Initial } \\
\text { Investment }\end{array}$ & $\$ 0$ & $\$ 34,320$ & $\$ 22,080$ & $\$ 0$ & $\$ 34,320$ & $\$ 14,800$ & $\$ 14,800$ & $\$ 17,920$ \\
\hline NPV & $(\$ 67,828)$ & $(\$ 8,645)$ & $\$ 2,694$ & $(\$ 66,491)$ & $(\$ 9,981)$ & $(\$ 64,700)$ & $(\$ 38,181)$ & $\$ 5,061$ \\
\hline $\begin{array}{l}\text { NPV (with } \\
\text { incentives) }\end{array}$ & & & $\$ 8,526$ & & & $(\$ 60,889)$ & $(\$ 34,369)$ & $\$ 9,750$ \\
\hline $\begin{array}{l}\text { Payback (years, } \\
\text { no incentives) }\end{array}$ & & 21.93 & 14.46 & & 23.1 & $>24$ & $>24$ & 12.60 \\
\hline $\begin{array}{l}\text { Payback (years, } \\
\text { solar incentives) }\end{array}$ & & & 6.45 & & & $>24$ & $>24$ & 4.27 \\
\hline $\begin{array}{l}\text { Option Value (no } \\
\text { incentives) }\end{array}$ & & $\$ 5,068$ & $\$ 24,426$ & & $\$ 1,077$ & $(\$ 42,285)$ & $(\$ 33,682)$ & $\$ 47,972$ \\
\hline
\end{tabular}

Table 7. DCF and ROA Valuations for a Single Home DG System Located in Suffolk County, New York (high NG price volatility) (nominal dollars)

\begin{tabular}{|c|c|c|c|c|c|c|c|c|}
\hline System Design & BAU & Gas Only & Solar+Gas & BAU & Gas Only & $\begin{array}{c}\text { Solar Only } \\
\text { (heating } \\
\text { included) }\end{array}$ & $\begin{array}{c}\text { Solar Only } \\
\text { (electricity } \\
\text { only) }\end{array}$ & Solar+Gas \\
\hline Electricity Rates & Standard & Standard & Standard & TOU & TOU & TOU & TOU & TOU \\
\hline Net Metering & No & No & No & Yes & Yes & Yes & Yes & Yes \\
\hline $\begin{array}{l}\text { Initial } \\
\text { Investment }\end{array}$ & $\$ 0$ & $\$ 34,320$ & $\$ 22,080$ & $\$ 0$ & $\$ 34,320$ & $\$ 14,800$ & $\$ 14,800$ & $\$ 17,920$ \\
\hline NPV & $(\$ 70,995)$ & $(\$ 12,469)$ & $(\$ 748)$ & $(\$ 69,659)$ & $(\$ 13,806)$ & $(\$ 67,868)$ & $(\$ 38,181)$ & $\$ 1,721$ \\
\hline $\begin{array}{l}\text { NPV (with } \\
\text { incentives) }\end{array}$ & & & $\$ 5,083$ & & & $(\$ 64,056)$ & $(\$ 34,369)$ & $\$ 6,410$ \\
\hline $\begin{array}{l}\text { Payback (years, } \\
\text { no incentives) }\end{array}$ & & $>24$ & 16.54 & & $>24$ & $>24$ & $>24$ & 14.65 \\
\hline $\begin{array}{l}\text { Payback (years, } \\
\text { solar incentives) }\end{array}$ & & & 7.79 & & & $>24$ & $>24$ & 6.07 \\
\hline $\begin{array}{l}\text { Option Value (no } \\
\text { incentives) }\end{array}$ & & $\$ 5,038$ & $\$ 20,820$ & & $\$ 3,047$ & $(\$ 18,107)$ & $(\$ 13,872)$ & $\$ 24,028$ \\
\hline
\end{tabular}

Table 8. DCF and ROA Valuations for a Critical Services Building (Hospital) DG System Located in Suffolk County, New York (baseline NG price volatility) (nominal dollars)

\begin{tabular}{|c|c|c|c|c|c|c|c|c|}
\hline System Design & BAU & NG-Only & Solar+Gas & BAU & NG-Only & $\begin{array}{l}\text { RE-Only } \\
\text { (heating } \\
\text { included) }\end{array}$ & $\begin{array}{c}\text { RE-Only } \\
\text { (electricity } \\
\text { only) }\end{array}$ & Solar+Gas \\
\hline Electricity Rates & Standard & Standard & Standard & TOU & TOU & TOU & TOU & TOU \\
\hline Net Metering & No & No & No & Yes & Yes & Yes & Yes & Yes \\
\hline $\begin{array}{l}\text { Initial } \\
\text { Investment }\end{array}$ & $\$ 0$ & $\$ 2.21 \mathrm{M}$ & $\$ 5.85 \mathrm{M}$ & $\$ 0$ & $\$ 2.21 \mathrm{M}$ & $\$ 3.6 \mathrm{M}$ & $\$ 3.6 \mathrm{M}$ & $\$ 5.85 \mathrm{M}$ \\
\hline NPV & $(\$ 17.9 \mathrm{M})$ & $\$ 8.10 \mathrm{M}$ & $\$ 6.99 \mathrm{M}$ & $(\$ 18.0 \mathrm{M})$ & $\$ 8.23 \mathrm{M}$ & $(\$ 15.9 \mathrm{M})$ & $(\$ 13.9 \mathrm{M})$ & $\$ 7.12 \mathrm{M}$ \\
\hline $\begin{array}{l}\text { NPV (with } \\
\text { incentives) }\end{array}$ & & & $\$ 8.46 \mathrm{M}$ & & & $(\$ 14.9 \mathrm{M})$ & $(\$ 12.9 \mathrm{M})$ & $\$ 8.59 \mathrm{M}$ \\
\hline $\begin{array}{l}\text { Payback (years, } \\
\text { no incentives) }\end{array}$ & & 2.51 & 4.98 & & 2.24 & $>30$ & $>30$ & 4.54 \\
\hline $\begin{array}{l}\text { Payback (years, } \\
\text { solar incentives) }\end{array}$ & & & 3.25 & & & $>30$ & $>30$ & 2.96 \\
\hline $\begin{array}{l}\text { Option Value (no } \\
\text { incentives) }\end{array}$ & & $\$ 104 \mathrm{M}$ & $\$ 119 \mathrm{M}$ & & $\$ 105 \mathrm{M}$ & $(\$ 16.7 \mathrm{M})$ & $(\$ 15.6 \mathrm{M})$ & $\$ 121 \mathrm{M}$ \\
\hline
\end{tabular}

Table 9. DCF and ROA Valuations for a Critical Services Building (Hospital) DG System Located in Suffolk County, New York (high NG price volatility) (nominal dollars)

\begin{tabular}{|c|c|c|c|c|c|c|c|c|}
\hline System Design & BAU & Gas Only & Solar+Gas & BAU & Gas Only & $\begin{array}{c}\text { Solar Only } \\
\text { (heating } \\
\text { included) }\end{array}$ & $\begin{array}{c}\text { Solar Only } \\
\text { (electricity } \\
\text { only) }\end{array}$ & Solar+Gas \\
\hline Electricity Rates & Standard & Standard & Standard & TOU & TOU & TOU & TOU & TOU \\
\hline Net Metering & No & No & No & Yes & Yes & Yes & Yes & Yes \\
\hline $\begin{array}{l}\text { Initial } \\
\text { Investment }\end{array}$ & $\$ 0$ & $\$ 2.21 \mathrm{M}$ & $\$ 5.85 \mathrm{M}$ & $\$ 0$ & $\$ 2.21 \mathrm{M}$ & $\$ 3.6 \mathrm{M}$ & $\$ 3.6 \mathrm{M}$ & $\$ 5.85 \mathrm{M}$ \\
\hline NPV & $(\$ 18.3 \mathrm{M})$ & $\$ 7.15 \mathrm{M}$ & $\$ 5.81 \mathrm{M}$ & $(\$ 18.4)$ & $\$ 7.28 \mathrm{M}$ & $(\$ 16.3 \mathrm{M})$ & $(\$ 13.9 \mathrm{M})$ & $\$ 5.93 \mathrm{M}$ \\
\hline
\end{tabular}




\begin{tabular}{|c|c|c|c|c|c|c|}
\hline $\begin{array}{l}\text { NPV (with } \\
\text { incentives) }\end{array}$ & & $\$ 7.27 \mathrm{M}$ & & $(\$ 15.3 \mathrm{M})$ & $(\$ 12.9 \mathrm{M})$ & $\$ 7.40 \mathrm{M}$ \\
\hline $\begin{array}{l}\text { Payback (years, } \\
\text { no incentives) }\end{array}$ & 2.69 & 5.76 & 2.38 & $>30$ & $>30$ & 5.01 \\
\hline $\begin{array}{l}\text { Payback (years, } \\
\text { solar } \\
\text { incentives) }\end{array}$ & & 3.51 & & $>30$ & $>30$ & 3.12 \\
\hline $\begin{array}{l}\text { Option Value } \\
\text { (no incentives) }\end{array}$ & $\$ 42.9 \mathrm{M}$ & $\$ 47.5 \mathrm{M}$ & $\$ 43.6 \mathrm{M}$ & $(\$ 7.0 \mathrm{M})$ & $(\$ 6.4 \mathrm{M})$ & $\$ 52.5 \mathrm{M}$ \\
\hline
\end{tabular}

\section{APPENDIX TABLES}

Table A1. DCF and ROA Valuations for a Single Home Residential Application Located in Waco, TX (baseline NG price volatility) (nominal dollars)

\begin{tabular}{|c|c|c|c|c|c|c|c|}
\hline System Design & BAU & Gas Only & Solar Only & Solar+Gas & BAU & Gas Only & Solar+Gas \\
\hline Electricity Rates & Standard & Standard & Standard & Standard & TOU & TOU & TOU \\
\hline Net Metering & No & No & No & No & Yes & Yes & Yes \\
\hline $\begin{array}{l}\text { Initial Investment } \\
\text { NPV }\end{array}$ & $\begin{array}{c}\$ 0 \\
(\$ 24,527)\end{array}$ & $\begin{array}{l}\$ 11,440 \\
(\$ 7,961)\end{array}$ & $\begin{array}{c}\$ 13,200 \\
(\$ 17,942)\end{array}$ & $\begin{array}{c}\$ 24,640 \\
(\$ 10,652)\end{array}$ & $\begin{array}{c}\$ 0 \\
(\$ 29,089)\end{array}$ & $\begin{array}{l}\$ 11,440 \\
(\$ 3,399)\end{array}$ & $\begin{array}{l}\$ 24,640 \\
(\$ 6,090)\end{array}$ \\
\hline $\begin{array}{l}\text { NPV (with } \\
\text { incentives) }\end{array}$ & & & $(\$ 16,642)$ & $(\$ 6,178)$ & & & $(\$ 671)$ \\
\hline $\begin{array}{l}\text { Payback (years, no } \\
\text { incentives) }\end{array}$ & & $>24$ & $>24$ & $>24$ & & 20.49 & 20.60 \\
\hline $\begin{array}{l}\text { Payback (years, } \\
\text { solar incentives) }\end{array}$ & & & $>24$ & 17.6 & & & 11.55 \\
\hline $\begin{array}{l}\text { Option Value (no } \\
\text { incentives) }\end{array}$ & & $(\$ 8,958)$ & $(\$ 26,094)$ & $(\$ 13,737)$ & & $\$ 3,092$ & $(\$ 5,439)$ \\
\hline
\end{tabular}

Table A2. DCF and ROA Valuations for a Critical Services Building (Hospital) DG System Located in Waco, TX (baseline NG price volatility) (nominal dollars)

\begin{tabular}{|c|c|c|c|c|c|c|c|}
\hline System Design & BAU & Gas Only & Solar Only & Solar+Gas & BAU & Gas Only & Solar+Gas \\
\hline Electricity Rates & Standard & Standard & Standard & Standard & TOU & TOU & TOU \\
\hline Net Metering & No & No & No & No & Yes & Yes & Yes \\
\hline $\begin{array}{l}\text { Initial Investment } \\
\text { NPV }\end{array}$ & $\begin{array}{c}\$ 0 \\
(\$ 13.0 \mathrm{M})\end{array}$ & $\begin{array}{l}\$ 3.3 \mathrm{M} \\
\$ 1.7 \mathrm{M}\end{array}$ & $\begin{array}{l}\$ 3.64 \mathrm{M} \\
(\$ 9.4 \mathrm{M})\end{array}$ & $\begin{array}{c}\$ 6.95 \mathrm{M} \\
(\$ 320,710)\end{array}$ & $\begin{array}{c}\$ 0 \\
(\$ 15.6 \mathrm{M})\end{array}$ & $\begin{array}{c}\$ 3.3 \mathrm{M} \\
\$ 2.35 \mathrm{M}\end{array}$ & $\begin{array}{c}\$ 6.95 \mathrm{M} \\
\$ 933,980\end{array}$ \\
\hline $\begin{array}{l}\text { NPV (with } \\
\text { incentives) }\end{array}$ & & & $(\$ 8.0 \mathrm{M})$ & $\$ 1.96 \mathrm{M}$ & & & $\$ 3.2 \mathrm{M}$ \\
\hline $\begin{array}{l}\text { Payback (years, no } \\
\text { incentives) }\end{array}$ & & 8.82 & $>30$ & 15.98 & & 7.46 & 12.27 \\
\hline $\begin{array}{l}\text { Payback (years, } \\
\text { solar incentives) }\end{array}$ & & & $>30$ & 6.92 & & & 5.06 \\
\hline $\begin{array}{l}\text { Option Value (no } \\
\text { incentives) }\end{array}$ & & $\$ 35.6 \mathrm{M}$ & $(\$ 12.9 \mathrm{M})$ & $\$ 36.5 \mathrm{M}$ & & $\$ 53 \mathrm{M}$ & $\$ 48.2 \mathrm{M}$ \\
\hline
\end{tabular}

